\title{
Developing a Research Program Within a Respiratory Care Department
}

\author{
Richard H Kallet
}

\author{
Introduction \\ Applied Science Education and Scientific Methodology \\ The Why and How of Developing a Research Program \\ Assessment: Resources and Opportunities \\ Types of Research \\ Bench-Top Studies \\ Writing a Review Paper \\ Retrospective and Quality Assurance Studies \\ Prospective Clinical or Laboratory Studies \\ Industry Sponsored Studies \\ Leadership and Mentorship \\ Summary
}

\begin{abstract}
Scientific research traditionally has been the domain of graduate school training, and it is based on higher cognitive levels associated with reflective thought. Such skills differ markedly from those needed to train competent respiratory therapists at the undergraduate level. Trainees at the undergraduate level need to acquire, comprehend, and apply large amounts of functional knowledge within a relatively brief time period. As a consequence, there is a pragmatic restriction on the level of complexity that characterizes pathophysiology, therapeutics, and associated technology that can be taught without causing confusion and thereby impeding the learning process. The era of evidence-based medicine is characterized both by the increasing complexity of medical technology and therapeutics. Because respiratory care is fundamentally a technology-driven profession, cultivating research skills among a select group of motivated practitioners is essential. Moreover, it is incumbent on all respiratory therapists to possess a rudimentary understanding of scientific methodology and a familiarity with the processes of reflective thought to become more discerning consumers of medical information. Organizing and implementing a research program within a respiratory care department or training program require forethought and devoted leadership. Crucial to this endeavor is developing mentors to guide those with little or no exposure to scientific inquiry. This article provides an overview of the pedagogical issues that underlie this predicament and then describes practical steps that can be taken to slowly build such a program. Key words: scientific methodology; reflective thought; research skills; health-care education; writing; scientific inquiry. [Respir Care 2020;65(3):388-399. (C) 2020 Daedalus Enterprises]
\end{abstract}

\section{Introduction}

Health-care education's primary focus is on subjects directly related to providing patient care. Therefore, despite the importance of research in this regard, it is

Mr Kallet is affiliated with the Respiratory Care Division, Department of Anesthesia and Perioperative Care, University of California-San Francisco, San Francisco General Hospital, San Francisco, California. necessarily of secondary importance. However, because respiratory care is fundamentally a technology-driven profession, perpetual advances in medical science and associated technologies necessitate that our profession continues to make concerted efforts to (1) develop

Mr Kallet discloses a relationship with the Asthma \& Allergy Prevention Company. 


\section{RESEARCH IN RESPIRATORY CARE}

research skills among a subset of therapists, and (2) ensure that such efforts also improve the sophistication of all practitioners in evaluating the information that research produces. Beginning in the early 1980s, a cadre of highly engaged respiratory therapists branched out to become ad hoc researchers, in part, motivated by technological advances in areas such as ventilator design, monitoring, and aerosol medicine. Those of us thus engaged during this time often did so without formal training. As someone on the "descending limb" of my research career, I am interested in ways that our profession might continue to cultivate therapist-researchers.

In this article, I discuss issues that I believe may help this endeavor. The first part of this article discusses important differences between the imperatives of educating students to become competent respiratory therapists versus those required to conduct competent research. The second part describes the conditions and opportunities available for initiating a research program, the attributes, and the skills required both for assuming leadership and/or mentorship roles and those of research trainees. This is based largely on my experiences as a researcher, clinical education coordinator, and mentor to clinicians who participated in and coauthored studies with me.

\section{Applied Science Education and Scientific Methodology}

"Wonder is the mother of all science."

John Dewey

\begin{abstract}
"The capacity to be puzzled is the premise of all creation, be it in art or in science ... It [creativity] requires the ability to accept conflict and tension and the courage to let go of certainties."
\end{abstract}

Erich Fromm

There are inherent contradictions in training respiratory therapists that touch on our participation in research. Students must learn numerous facts and concepts in a relatively brief time period to become functioning practitioners. This challenging experience tends to influence attitudes toward knowledge long afterward. The dynamism of science is based on acceptance that our knowledge largely is incomplete and, therefore, tentative. This, in turn, requires frequent re-evaluation with regard to how our knowledge has been constructed, the strength of the evidence that supports it, and the soundness of the logical inferences drawn

Correspondence: Richard H Kallet MSc RRT FAARC, 2070 Fell St. Apt 1, San Francisco, CA 94117. E-mail: richkallet@gmail.com.

DOI: $10.4187 /$ respcare. 07478 from it, so that this knowledge can be either reaffirmed or revised, and thus advanced.

This process is formally known as reflective thought, which is the "active, persistent, and careful consideration of any belief or supposed form of knowledge in the light of the grounds that support it and the further conclusions to which it tends" and is characterized by a "state of perplexity, hesitation, doubt; and an active search or investigation directed toward bringing to light further facts which serve to corroborate or to nullify the suggested belief." This forms the basis of scientific inquiry, which is "rigorous, methodical, academic, logical, and practical" and constitutes "the very facility that gives us a clear understanding of seeing things sharply in focus." 2

Reflective thought occurs through cognitive accretion. A crucial element is possessing a depth and understanding of a subject before an individual can (1) critically evaluate the quality or veracity of knowledge, (2) accurately detect inconsistencies that might exist within a body of knowledge, and (3) recognize when conjecture and hypotheses are used to fill in unavoidable gaps in knowledge. In other words, one must fully comprehend what is known about a subject before one can adequately critique it. This necessitates higher-level cognitive skills of analysis, synthesis, and evaluation, which, in turn, requires substantial self-motivation and patience to master. ${ }^{3}$

But herein lies the nettlesome problem. First, how much of the inherent complexity that characterizes pathophysiology, therapeutics, and associated technology can realistically be conveyed to students (or clinicians) without hopelessly confusing them? In other words, what are students and clinicians actually required to know and comprehend to function effectively in a complex, ever-evolving, evidence-based, technology-driven environment. Second, is the impossibility of trying to cultivate reflective thought about pertinent subject matter concurrently with trying to teach it. The crux of the problem is in determining when and how, and to what degree reflective thought relevant to our professional focus might be broached, either in an undergraduate program or as part of ongoing educational efforts.

This conundrum is neither surprising nor new, because it represents the traditional purpose of graduate school (particularly doctoral programs), namely, mastering the art of reflective thought, or slow thinking. ${ }^{4}$ In contrast, teaching applied science at the associate and baccalaureate levels necessitates stressing the main characteristics of phenomena and related concepts. These characteristics represent elegant and effective approximations of reality. This strategy, however, can only hint at the cognitive and empirical processes by which such knowledge was generated. In other words, we do not teach science as a discipline but rather the fruits of scientific inquiry. Unfortunately, these 


\section{RESEARCH IN RESPIRATORY CARE}

approximations are construed as unambiguous reality by those immersed in training.

There are professional implications that arise from this dichotomy. Our training and subsequent employment experiences tend to reinforce a reliance on relatively simplistic explanations and take-home messages that are construed as unassailable reality. As a consequence, this promotes an impression that further reflection generally is unwarranted. Instilling such confidence is both helpful and problematic. To function competently, often under extraordinarily stressful situations, we rely on a sense of confidence and control mediated through our knowledge and understanding. Possessing such practical ("working") knowledge is crucial because it allows decisive and effective responses to clinical situations. Unfortunately, this sometimes can cause profound misjudgments in particularly complex cases. Moreover, reliance on working knowledge has some unintended and unconstructive tendencies that often manifest either as resistance toward or uncritical acceptance of new information.

These tendencies can be a significant obstacle to our profession's advancement in this era of evidence-based medicine and rapidly evolving technology. Like all health-care professions, there needs to be a cadre of respiratory therapists willing to commit themselves to advancing the science of respiratory care and becoming the profession's scientific intelligentsia. At the same time, all members of the profession need to possess some understanding and appreciation of how science functions as a discipline and have a respect for the limitations of knowledge at any particular time point.

\section{The Why and How of Developing a Research Program}

So, what then does cultivation of a research program offer our profession and how can this be accomplished? If done properly, research opportunities create an environment in which the principles of scientific inquiry can be introduced. This is best achieved through creating hands-on experiences wherein students and therapists actively engage in a well-structured research project. Historically, this is how scientific inquiry was taught. It "is a practical art . . not learned out of books, but by imitation and experience," through apprenticeship wherein the trainee is given an interesting problem to solve along with assistance, encouragement and critical feedback. ${ }^{2}$

What constitutes an interesting problem during the training of students may be abstract concepts presented didactically that can be reinforced and elaborated on in a laboratory setting. For experienced clinicians, this may involve delving into perplexing issues encountered at the bedside or in understanding how new technology works. In this manner, we are in concordance with what true science has been about since its origins, namely, puzzle solving. ${ }^{5}$ When done correctly, and for the right motivation, participation in research is a profound educational experience. Once subjected to rigorous scientific inquiry, clinical problems that first seem straightforward very often reveal a much more complex puzzle. These humbling, invaluable experiences were captured by the Danish mathematician Piet Hein who quipped: "problems worthy of attack prove their worth by hitting back." 6

\section{Assessment: Resources and Opportunities}

Developing a research program can be organized into categories and queries that help evaluate both the feasibility and the initial approach (Table 1). These might include considerations with regard to (1) topics to explore that are workable and have clinical relevance to the department, (2) availability of equipment or space needed to conduct research, (3) whether there are staff with sufficient interest and enthusiasm to carry a project to completion, and (4) the opportunity to participate in other research projects within the institution. Other related issues, such as how to develop research skills and goals that foster motivation, are discussed below.

\section{Types of Research}

There are practical limitations in organizing a research program. The short-term goal should be aimed at readily achievable, relatively uncomplicated projects that involve a minimum of bureaucratic processes (ie, avoiding those projects that involve human or animal subject protection or that enter into contracts with private industry).

\section{Bench-Top Studies}

Bench-top studies have relatively few logistical impediments. Areas of study can include performance evaluations of ventilators, oxygen delivery devices, nebulizers, artificial airways, monitors, and so forth. Although these topics have been well explored, they remain valuable, both for teaching research skills and for enhancing trainee's clinical competency.

Early on, the primary objective should be teaching research methodology and guiding trainees on how to construct an investigation. Once a topic is chosen, preliminary sessions should focus on information gathering, whereby pertinent literature is studied and discussed (Table 2). This includes how previous investigations approached the same problem and formulated their study question, the current state of knowledge produced by these studies, and what aspects of the topic remain controversial or unanswered. Moreover, attention should focus on the logical consistency used to generate the study hypothesis and the methods developed in attempting to answer it. This may illuminate 


\section{RESEARCH IN RESPIRATORY CARE}

Table 1. Important Considerations When Organizing a Research Program

Questions to Consider

What research issue(s) do you want to investigate and how should this be prioritized?

Do you have the resources necessary to investigate these issues?

How much interest is there in developing a research program?

How best to develop research skills and maintain enthusiasm within a department?

What are the characteristics needed to build credibility within the profession?
Comments

Start slow/aim low: Choose a single project that is realistically attainable and can be completed within a reasonable time period (eg, 6 months)

Clinical relevance: The initial project should focus on a current or lingering topic or problem that would interest some staff members and motivate their participation

Do your homework: Before initiating a project, perform a literature search to fully understand what is known about the topic and whether there are unanswered questions or controversies about the topic

Is there physical space in which to conduct a bench study or to review medical records

Is there a local IRB or other administrative body that could approve limited use of PHI?

Is there a medical library available to conduct literature searches?

Is the medical director supportive of department-initiated research; are other physicians interested in providing guidance or in taking on a role as a principal or co-investigator for projects that require IRB approval?

Are there funds or grants available to purchase or rent equipment needed to conduct a study?

Those most likely to dependably participate in research projects are those who

- take on a leadership role by volunteering to assist with such projects as equipment evaluation or quality-assurance monitoring

- enjoy mentoring new employees, act as clinical adjunct instructors, volunteer to present in-service lectures, are viewed by other staff members as a valuable resource

- frequently attend conferences and/or stay current by regularly reading RESPIRATORY CARE and other journals

- actively participate in multi-disciplinary rounds; have developed a rapport with those in other clinical services who view them as valuable resources

Begin with readily achievable small projects that can be completed within a reasonable time period (6-8 months)

Encourage participation and develop a team approach to projects

Instruct team members on using search engines, eg, PubMed, and then encourage trainees to work together on literature searches

Have regular research meetings; discussions should include results of literature reviews and how they might inform the design of their study, debriefing sessions to review issues that arise during research sessions, reviewing study results, and developing abstracts and poster presentations

Present findings at staff meetings and, when appropriate, interdisciplinary care meetings or forums

Set an expectation that each project will be written up and submitted for presentation at the AARC's Open Forum, state or local conferences, and symposiums

Do not design a study or manipulate statistics to try and prove a belief; it will be immediately transparent to seasoned researchers

The key to good research is in maintaining an agnostic attitude toward your project; one should strive for open mindedness and healthy skepticism; always begin designing a study based on the premise that there is no difference between the therapy or technology of interest and with what it is being compared (ie, testing the null hypothesis)

Avoid drawing conclusions not directly supported by your results (overstating your results)

Be cautious and circumspect in the use of language (eg, avoid language such as "this proves"); use tentative language that reinforces the reality that our findings are preliminary and subject to both error and unrecognized bias; use words such as "suggest" and "may" or "invites speculation"

Accept criticism gracefully and respond to it in a respectful manner 


\section{RESEARCH IN RESPIRATORY CARE}

Table 2. How to Build and Execute a Bench-Top Study Design*

\begin{tabular}{|c|c|}
\hline Step & Issues To Be Addressed \\
\hline Choosing a topic & $\begin{array}{l}\text { Relevance of a topic or problem to departmental needs } \\
\text { Level of enthusiasm among staff members to participate in the study }\end{array}$ \\
\hline Information gathering & 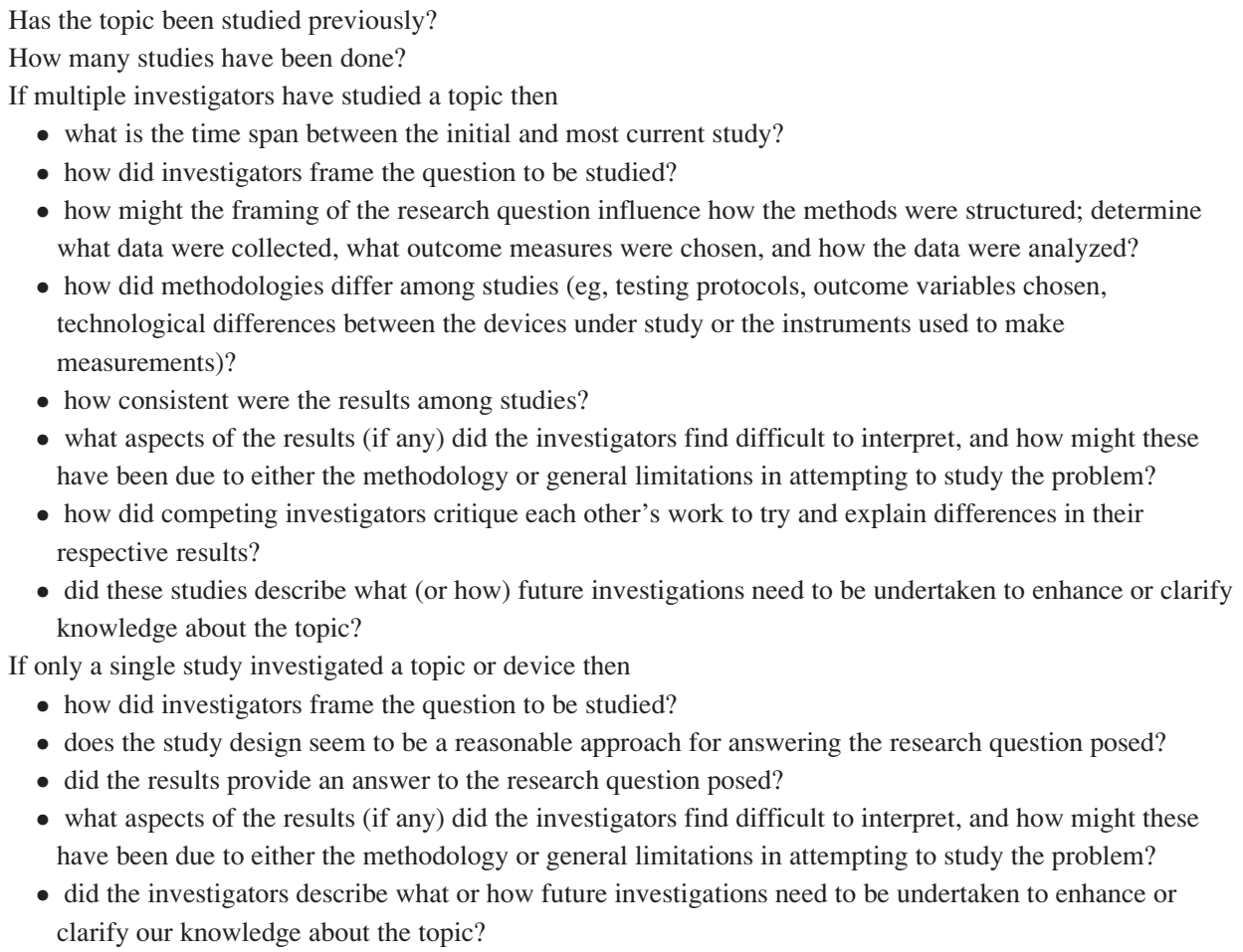 \\
\hline
\end{tabular}

When comparing study methodology: What can be learned from a previous study(s)?

Planning the design
Is this topic worth pursuing?

Are we attempting to answer the same research question?

Are there different ways to frame the research question?

Are we interested in approaching the same problem or are we interested in studying areas on the topic that remain unanswered, controversial, or simply puzzling?

Were previous study designs adequate to address the research question posed?

Are there aspects of other study designs that should be incorporated into our study, and how would this help us answer our research question?

Are there obvious pitfalls or other inadequacies in previous investigations that can be avoided?

To answer our research question should different

- types of measurements be made?

- instruments be used?

- variables be compared?

- statistical approaches be used to analyze our data?

Formulating the research question

Is the research question simplistic or multifaceted?

Determine what are the dependent and independent variables based on the question asked

How will they be measured?

How many comparisons need to be made to adequately address the research question (ie, are there multiple factors or aspects that need to be addressed to answer the research question?)

Determine potential confounding variables; the degree to which they can be controlled and how to account for them

Create a database that captures all variables of interest; ensure that any data-collection form is structured so that variables are written down in the same exact order that they will be entered into the database

Ensure that the protocol design is comprehensive and can adequately answer the research question

Determine the statistical test(s) that will be needed to analyze the data

(Continued) 


\section{RESEARCH IN RESPIRATORY CARE}

Table 2. Continued

\begin{tabular}{|c|c|}
\hline Step & Issues To Be Addressed \\
\hline Organization & $\begin{array}{l}\text { Availability of objective experienced researchers (ie, those not associated with the study) to critique the study } \\
\text { question, design, and statistical methods; consider obtaining a consult from a statistician clinical studies } \\
\text { Modify the design as needed based on outside feedback and also after further contemplation by members of the } \\
\text { research team } \\
\text { Do we have or can we acquire the equipment needed to conduct the study? } \\
\text { Is there adequate space and time available to execute the study? } \\
\text { How many tasks are required during an experimental run for } \\
\text { - setup and disassembly of the experiment, } \\
\text { - manipulation and monitoring of the equipment during testing } \\
\text { - note taking that chronicles the process, including problems encountered; modifications made (or needed) } \\
\text { to address problems, and interesting observations and/or questions that arise during an experimental run } \\
\text { What is the minimum number of co-investigators needed to execute an experimental session? } \\
\text { How will these be assigned? } \\
\text { What is the minimum number of sessions anticipated to compete the experiment? } \\
\text { Scheduling regular debriefing sessions to review experimental sessions and following interim analyses of the } \\
\text { data } \\
\text { How will data be captured and transferred into a database? } \\
\text { How will the database be organized? } \\
\text { Can the data be imported easily to a statistics program? } \\
\text { Who will perform the data analysis? } \\
\text { Who will write up the experiment as an abstract (and potentially as a manuscript)? }\end{array}$ \\
\hline
\end{tabular}

* Many of the steps and issues in this table are applicable to other types of research.

why different investigations on the same topic often produce dissimilar results. These steps in study organization also apply to other types of investigations.

The study hypothesis focuses attention on an expected outcome. Therefore, any unexpected outcome or puzzling occurrence during an experiment must be scrutinized. The first approach always is to determine whether it is explained by a faulty technique, inadequate equipment, measurement or transcription error, or a design flaw. The latter raises questions as to whether the original design was adequate to test the hypothesis or, more fundamentally, was there an aspect of the problem that conceptually was misapprehended? When those issues have been reviewed and addressed, the original hypothesis (or a new iteration) is tested to verify or reject it. Although invariably frustrating, unexpected occurrences often produce some of the most valuable learning experiences in becoming a researcher.

Another approach to bench testing is investigating whether trainees can replicate what other studies found when using (if possible) the same methodology. Even when verification is elusive, it teaches the importance of how methodological differences may substantially alter study results and the conclusions drawn from them. Moreover, because only a limited number of variables are studied, bench-top studies are an elegant means of introducing the concepts of dependent, independent, and confounding variables.
Bench-top studies also can be used to mimic unusual clinical phenomena that might improve a trainee's understanding. For example, a subject we enrolled into the ARDSNet ARMA trial ${ }^{7}$ developed acute pulmonary edema during an episode of severe patient-ventilator asynchrony. Lung modeling of the incident afterward indicated that the apparent cause was related to patient-ventilator tidal volume mismatching. ${ }^{8}$ We subsequently confirmed and expanded these initial findings by a more comprehensive lung modeling study, followed by prospective clinical studies. ${ }^{9-11}$

\section{Writing a Review Paper}

An essential element in research is acquiring literature review skills and learning how to analyze studies critically; the most fruitful end result is a published review paper. As discussed above, meaningful research begins with accruing knowledge about what investigators have previously done and discovered. This includes how a problem has been approached in terms of previous knowledge, conceptual formulation, methodological construction, and presentation of results and their interpretation. It is important to witness how other investigators intellectually engage themselves and others when confronting ambiguity, contradiction, and failure. This discourse indirectly illuminates the philosophical thought processes on which scientific inquiry rests. It also provides an historical context for 


\section{RESEARCH IN RESPIRATORY CARE}

understanding the evolutionary process by which a problem comes to be understood more fully as a result of scientific debate.

Writing a review paper that attempts to reconcile controversies that arise from numerous scientific inquiries is arduous. A realistic initial goal for trainees is to describe what these arguments are, whether themes or trends emerge across the studies, and then venture a judgment as to which arguments seem to be more plausible and well reasoned. This process requires systematic organization and synopses of the studies that can be used to create a coherent narrative. Moreover, it requires detachment from the topic that postpones judgment and avoids the tendency to overidentify oneself with a particular impression at the project's inception.

Finally, scientific writing requires clear, concise, and direct communication. This, in turn, enhances cognitive skills crucial for participating in scientific discourse. It should be noted that submitting a manuscript for peer review is a process similar to that required for a doctoral dissertation. Early on, this process is intimidating and often overwhelming. Yet, it is a necessary and invaluable growth experience because it exposes our unrecognized biases and flawed arguments as well as provides new insights into the topic and how it might be approached, and always results in a higher-quality paper and a more valuable contribution to the medical literature.

\section{Retrospective and Quality Assurance Studies}

A higher level of scientific complexity is afforded when performing retrospective analysis by using medical records. Potential topics may include a cohort of subjects apparently treated successfully with a therapy not widely practiced or a disease not widely encountered. Another topic may be to examine outcomes associated with implementing a standardized care protocol.

These types of studies introduce more complex issues that involve uncontrolled (confounding) variables that require very thoughtful data collection of numerous variables and more sophisticated statistical testing to account (ie, control) for confounders. These studies both challenge the problem-solving capacity of trainees and, subsequently, sharpen their focus and critical faculties when they evaluate other studies. Moreover, engaging in retrospective or quality assurance studies foster fosters an appreciation for the ambivalent relation between cause and effect when trainees evaluate the impact of therapies they administer during clinical practice.

All studies in this category necessarily involve oversight and approval by institutional review boards that govern human subjects' protection. They also may require a physician's participation as the supervising or principle investigator to obtain approval. Because both retrospective studies and post hoc analysis of time-series quality assurance initiatives fall under the purview of clinical practice (ie, subjects are not being randomized to receive different care), the primary issue is in safeguarding protected health information. Therefore, trainee investigators must be diligent in protecting subjects' health information.

\section{Prospective Clinical or Laboratory Studies}

Participation in another investigator's clinical trials can be a valuable part of a department-based research program. However, the potential educational and training benefits must be considered carefully. The questions to weigh are as follows. How much actual mentoring will take place and by whom? How much time commitment over how long of a period will be required to complete the project? Are there department members willing to make such a commitment? How many trainees will benefit from the experience? Does such participation enhance the reputation and perception of the department within the institution? Will there be some form of salary support or other forms of departmental compensation offered for such participation?

\section{Industry Sponsored Studies}

When initiating a research program, participating in industry-sponsored studies probably should be avoided. There is a distinction, however, between projects that provide data for a company's internal use for product development and/or refinement versus those used for publications that support product marketing. The former situation may be valuable because trainees likely will interact with engineers and highly knowledgeable product specialists. The latter situation is problematic because the goals of scientific inquiry are not necessarily concordant with those whose primary motivation is in capturing or in expanding a product's market share. This invariably creates the risk of bias in study design and interpretation of results. It is in the interest of both parties that these studies are undertaken by established researchers more comfortable and adept at negotiating the terms and boundaries of study execution.

\section{Leadership and Mentorship}

Organizing a research program within a department or an academic program requires initiative and perseverance as well as leadership and mentorship. The last 2 characteristics are problematic if the program organizer lacks experience. In that situation, the organizers should seek mentorship for themselves or else postpone initiating a program until they become acquainted with research methodology. There are numerous resources available on research design, scientific 


\section{RESEARCH IN RESPIRATORY CARE}

Table 3. Resources for Creating a Research Program and Mentoring Novice Researchers

\begin{tabular}{|c|c|}
\hline Resource & Description \\
\hline $\begin{array}{l}\text { Chatburn RL. Handbook for health care research. 2nd edition. Boston, } \\
\text { MA: Jones and Bartlett; } 2011\end{array}$ & A comprehensive resource on how to conduct research \\
\hline $\begin{array}{l}\text { Zeiger M. Essentials of writing biomedical research papers. 2nd edition. } \\
\text { New York: McGraw-Hill; } 2000\end{array}$ & An excellent guide for developing scientific writing skills \\
\hline $\begin{array}{l}\text { Evans H. Do I make myself clear? Why writing well matters. New York: } \\
\text { Little, Brown; } 2017\end{array}$ & $\begin{array}{l}\text { Another excellent book by the former editor of The Times (of London), with } \\
\text { numerous examples of how to reduce verbiage and write prose in a direct } \\
\text { and minimalist manner that is essential for publishing in the medical } \\
\text { literature }\end{array}$ \\
\hline $\begin{array}{l}\text { Branson RD. Anatomy of a research paper. Respir Care 2004;49(10) } \\
\text { 1222-28 }\end{array}$ & $\begin{array}{l}\text { Another invaluable and highly accessible guide to writing a research paper } \\
\text { that covers each section required in a scientific manuscript }\end{array}$ \\
\hline $\begin{array}{l}\text { Okasha S. Philosophy of science. A very short introduction. 2nd edition. } \\
\text { Oxford: Oxford University Press; } 2016\end{array}$ & $\begin{array}{l}\text { An excellent, accessible primer for understanding the philosophy of science } \\
\text { that helps explain the rationale behind clinical research methodology; } \\
\text { another excellent background resource }\end{array}$ \\
\hline $\begin{array}{l}\text { Kahneman D. Thinking fast and slow. New York: Farrar, Straus and } \\
\text { Giroux; } 2011\end{array}$ & $\begin{array}{l}\text { A fascinating exploration into the psychology of cognition that describes the } \\
2 \text { systems that drive thought; excellent background reading, which pro- } \\
\text { vides enormous depth to understanding the common pitfalls that stymie } \\
\text { our capacity for judgment and decision-making }\end{array}$ \\
\hline $\begin{array}{l}\text { Dewey J. How we think (originally published in 1910). Mineola, NY: } \\
\text { Dover; } 1997\end{array}$ & $\begin{array}{l}\text { A classic treatise on cognition by one the preeminent American philoso- } \\
\text { phers of the 19th and 20th centuries; another excellent background source } \\
\text { that was written for the lay public }\end{array}$ \\
\hline
\end{tabular}

writing, critical thinking skills, and the philosophical principles that undergird scientific methodology (Table 3).

Leadership and mentorship are distinct but intertwined traits. Among these traits are initiative, disciplined persistence, sensitivity, and creativity, and modeling behavior that exemplifies the scientific attitude toward inquiry and testing. It requires building a structure that fosters teamwork and continuous education. The crux of this structure is planning and directing meetings in which team members are oriented to a project, basic research concepts are introduced, and scheduling experimental runs coupled with debriefing meetings to review what transpired. In addition, a good way to build teamwork is to assign members specific tasks on a rotating basis during a particular experimental run. This strengthens team cohesion by sharing experiences that allow members to assist one another.

A competent mentor is present during all experimental runs to observe trainee technique and troubleshoot problems, and to take advantage of every "teaching moment." This is accomplished by drawing attention to variability in technique among trainees, by focusing on details, and by improving their troubleshooting, observational, and data collection skills. Teaching moments also include continually reinforcing research concepts and expanding the trainees' knowledge about the topic under investigation. Only after the mentor is confident in a trainee's skills and work habits should the trainee be allowed to work independently. This recognition of achieving competency is itself motivating and builds self-confidence.
Scientists typically do not require trainees to have formal training in logic, nor must trainees meticulously defend research projects through a step-by-step process (as philosophers are required to do). This often leads to elementary errors in logic used both in constructing hypotheses and in interpreting results. ${ }^{2}$ Fortunately, the logic used in constructing scientific arguments is not particularly greater than that used when carefully deconstructing everyday problems. ${ }^{2}$ Therefore, during the course of an experiment, both new and experienced investigators should be mindful to evaluate their reasoning to ensure that it is formulated in a logical and consistent manner. If omitted, such issues inevitably will be pointed out during the peer review process and may make the entire project unpublishable.

Leadership and/or mentorship also involves identifying and encouraging staff who likely possess the aptitude and discipline to help conduct and complete a project. In my own experience as a young therapist excited about participating in a study, I was not aware of, nor was I particularly interested in, the rationale on which study design was based. This is common and a natural part of the process of becoming a researcher. It should be welcomed by the mentor as a teaching challenge. Part of mentorship is cultivating a trainee's enthusiasm, interest level, and curiosity. Aspects of this include encouraging and rewarding those who are dependable participants, show initiative in problem-solving, volunteer to help work on particular aspects of a project (eg, setting up a database, investigating technical questions that arise). Trainees with the potential to assume 


\section{RESEARCH IN RESPIRATORY CARE}

Table 4. Sample Structure for Guiding Trainees on How to Review and Discuss the Study Results*

\begin{tabular}{|c|c|}
\hline Topic & Discussion Elements \\
\hline Reviewing the results & $\begin{array}{l}\text { Descriptive statistics: provide a simplified explanation of the concepts of central tendency vs dispersion in } \\
\text { data } \\
\text { Inferential testing: provide a simplified explanation of or why specific tests are used, given the study } \\
\text { methodology } \\
\text { Significance level: provide a simplified explanation of probability and differentiate between statistical and } \\
\text { clinically meaningful differences } \\
\text { Which, if any results were statistically significant? } \\
\text { If significant results were found, did they involve independent, dependent, or potential confounding } \\
\text { variables? } \\
\text { How large of a difference was found in the (dependent) variable of interest ("signal strength") }\end{array}$ \\
\hline Interpreting the results & $\begin{array}{l}\text { What were the main results of the study? } \\
\text { Was the study hypothesis confirmed or rejected? } \\
\text { What inferences can be drawn from results that were statistically different vs those that were not? } \\
\text { Was there sufficient power to adequately test the hypothesis (ie, how much confidence can be placed on the } \\
\text { findings)? } \\
\text { What are the overall implications of the study results? }\end{array}$ \\
\hline Methodological issues & $\begin{array}{l}\text { Was the study protocol or measurement technique altered during the course of the study? } \\
\text { Was there any evidence that the quality or consistency of data varied according to which investigator was } \\
\text { manipulating the study variables or recording the measurements (interobserver variability)? } \\
\text { If yes, then should a post-hoc analysis done to evaluate whether these alterations might have influenced the } \\
\text { results? } \\
\text { Were there incidences of failure in trying to control any confounding variables present during the study? } \\
\text { Were these incidences systemic in nature or limited to specific subjects or experimental runs? } \\
\text { If it involved a subset of subjects or study runs, then should a post hoc analysis be done to evaluate whether } \\
\text { deselecting these incidences might have influenced the results? }\end{array}$ \\
\hline Evaluating study validity & $\begin{array}{l}\text { Provide a simplified explanation of internal vs external validity; discuss how answers to the methodological } \\
\text { issues raised above might impact internal validity } \\
\text { Review what or who was studied and explain how these testing conditions limit speculation about how the } \\
\text { results may be applied to the larger patient population that receives this therapy or is treated with or moni- } \\
\text { tored with the device that was tested (ie, generalizability) }\end{array}$ \\
\hline $\begin{array}{l}\text { Placing the study results within } \\
\text { a larger research context }\end{array}$ & $\begin{array}{l}\text { Are the study results consistent with or do they deviate from previous studies on the same topic? } \\
\text { What methodological differences might account for both similar and dissimilar results between studies? } \\
\text { What implications might issue from these differences or similarities in either findings or methodology? } \\
\text { What, if any, further studies need to be done on this topic and how might lessons from the current study might } \\
\text { inform the design of future studies? }\end{array}$ \\
\hline Overall study assessment & $\begin{array}{l}\text { What are the strengths of the current study (ie, how might it further our collective understanding of the } \\
\text { topic)? } \\
\text { What are the limitations of the current study (ie, how might the design or difficulty in controlling either the in- } \\
\text { dependent or confounding variables have produced uncertain or questionable results)? }\end{array}$ \\
\hline
\end{tabular}

*Some of these questions can be incorporated into debriefing meetings after an experimental run.

leadership roles will likely exhibit a strong desire to immerse themselves in reading on the topic being studied, spontaneously engage in theoretical speculation related to what is being observed, or in thinking about how to develop new studies suggested from the results of the current project.

Probably the greatest reward is presenting an abstract at a conference and seeing one's name associated with a published abstract or manuscript. All participants should be encouraged to present their results in a public forum. Often a project can be subdivided into topics, each of which can be presented separately as an abstract by a team member. ${ }^{12-14}$ The most beneficial scientific experience is when a trainee presents and defends an entire abstract on his or her own.

Because research is graduate school-level work, it is unrealistic to expect trainees with an undergraduate education to readily acquire the necessary cognitive skills without considerable help. Early on, the mentor will largely be responsible for writing abstracts, guiding the preparation of the oral summary of the poster, and developing a manuscript for submission to a peerreviewed journal. 
RESEARCH IN RESPIRATORY CARE

Table 5. A Model for Organizing a Brief Oral Summary of a Poster Presentation*

\begin{tabular}{|c|c|c|}
\hline Section & Comments & Example \\
\hline \multirow[t]{4}{*}{ Background } & State what was studied & $\begin{array}{l}\text { We studied the impact of different inspiratory flow pat- } \\
\text { terns on subject WOB }\end{array}$ \\
\hline & $\begin{array}{l}\text { Briefly state the premise of the study, the hy- } \\
\text { pothesis being tested or research question(s) } \\
\text { being asked and the logic by justifying the hy- } \\
\text { pothesis or question being tested }\end{array}$ & $\begin{array}{l}\text { 1. The premise of our study was that the ventilator's } \\
\text { initial peak inspiratory flow would affect subject } \\
\text { WOB because a patient's peak flow demand occurs } \\
\text { at } \sim 25 \% \text { of inspiratory time }\end{array}$ \\
\hline & & $\begin{array}{l}\text { 2. Our hypothesis was that, for a fixed inspiratory } \\
\text { time and tidal volume, a decreasing ramp flow pat- } \\
\text { tern would reduce subject WOB more than a con- } \\
\text { stant flow pattern }\end{array}$ \\
\hline & & $\begin{array}{l}\text { 3. We reasoned that this would be the expected out- } \\
\text { come because the initial peak flow must be higher } \\
\text { with a decreasing ramp pattern under these test } \\
\text { conditions }\end{array}$ \\
\hline \multirow[t]{4}{*}{ Methods } & $\begin{array}{l}\text { In 3-4 brief sentences: state what was measured } \\
\text { or compared }\end{array}$ & $\begin{array}{l}\text { 1. Our design used a randomized, time series, cross- } \\
\text { over approach }\end{array}$ \\
\hline & & $\begin{array}{l}\text { 2. The primary dependent variable of interest was } \\
\text { subject WOB and was measured by using esopha- } \\
\text { geal manometry }\end{array}$ \\
\hline & & $\begin{array}{l}\text { 3. We compared the decreasing ramp and constant } \\
\text { flow patterns (independent variables) in volume } \\
\text { control ventilation; the tidal volume, inspiratory } \\
\text { time and set frequency used for clinical manage- } \\
\text { ment to limit the potential impact of confounding } \\
\text { variables on subject WOB }\end{array}$ \\
\hline & & $\begin{array}{l}\text { 4. Ten subjects were studied over } 15 \mathrm{~min} \text { on each set- } \\
\text { ting, and data were collected during the last } 5 \mathrm{~min}\end{array}$ \\
\hline \multirow[t]{4}{*}{ Results } & $\begin{array}{l}\text { In 3-4 brief sentences: state the most important } \\
\text { finding(s) directly related to the study } \\
\text { question }\end{array}$ & $\begin{array}{l}\text { 1. We found modest statistically significant reduc- } \\
\text { tions in subject WOB with the decreasing ramp } \\
\text { pattern }\end{array}$ \\
\hline & $\begin{array}{l}\text { State whether there were problems in executing } \\
\text { the study or unusual and/or unexpected }\end{array}$ & $\begin{array}{l}\text { 2. This finding was associated with significantly } \\
\text { higher peak flows with the decreasing ramp pattern }\end{array}$ \\
\hline & findings. & $\begin{array}{l}\text { 3. No other measurements of ventilator variables } \\
\text { were different between test conditions }\end{array}$ \\
\hline & & $\begin{array}{l}\text { 4. We also noted marked variability among subjects } \\
\text { both in the magnitude of WOB and the relative } \\
\text { reduction in WOB among flow patterns }\end{array}$ \\
\hline Conclusions and discussion & $\begin{array}{l}\text { In 3-4 brief sentences: state whether the hypoth- } \\
\text { esis or test question was confirmed or rejected } \\
\text { by the study results. This should include both } \\
\text { the strengths and limitations of the study, and } \\
\text { also whether further studies are needed to re- }\end{array}$ & $\begin{array}{l}\text { 1. Our findings support our hypothesis that higher ini- } \\
\text { tial peak flows seem to reduce subject WOB; how- } \\
\text { ever, the differences in WOB were modest for the } \\
\text { entire study sample and varied among some } \\
\text { subjects }\end{array}$ \\
\hline & $\begin{array}{l}\text { affirm, extend, clarify or address limitations in } \\
\text { the current study }\end{array}$ & $\begin{array}{l}\text { 2. The strength of our study was that we used subjects } \\
\text { as their own controls and used brief measurement } \\
\text { periods to prevent other time-related factors (eg, } \\
\text { development of fever, change in the level of pain } \\
\text { and/or anxiety) from influencing our results; we } \\
\text { also kept the baseline minute ventilation, tidal vol- } \\
\text { ume, and inspiratory time constant as well as } \mathrm{F}_{\mathrm{IO}_{2}} \\
\text { and PEEP to control other variables that might } \\
\text { influence subject WOB }\end{array}$ \\
\hline
\end{tabular}

(Continued) 


\section{RESEARCH IN RESPIRATORY CARE}

Table 5. Continued

\begin{tabular}{|c|c|c|}
\hline Section & Comments & Example \\
\hline & & $\begin{array}{l}\text { 3. The major limitations of our study: only } 10 \text { sub- } \\
\text { jects were investigated, which limits our ability to } \\
\text { generalize our results to other patients under differ- } \\
\text { ent conditions; in addition, we did not control or } \\
\text { assess other variables that may influenced } \mathrm{WOB} \\
\text { (eg, level of sedation and analgesia, } \mathrm{pH} \text {, and } \mathrm{P}_{\mathrm{aCO}} \\
\text { were not measured) } \\
\text { 4. Further studies should be undertaken with a larger } \\
\text { sample size to try and replicate our results and also } \\
\text { attempt control the level of sedation within a well- } \\
\text { defined range }\end{array}$ \\
\hline
\end{tabular}

* Professional societies differ in how they want abstracts to be presented, so this model may need to be modified accordingly; the elements, however, are useful in preparing for the typical questions raised by moderators and audience members.

WOB $=$ work of breathing

After the completion of data collection and the initial statistical analysis, a series of meetings should be held to discuss the results and prepare presentations. The initial post-completion meetings should guide trainees through a review structured similar to that used in the discussion section of a research paper (Table 4). Subsequent meetings should concentrate on presentation development. Trainees should be shown the process of writing an abstract. Afterward, trainees should write a draft of an oral presentation for the poster session. Often this is a $2-3$ min summary that encompasses not only the results but the main structural and cognitive elements of the study (Table 5). Subsequent meetings should focus on reviewing and revising trainee's draft presentations, designing and producing posters, and rehearsing the oral presentations. Poster presentations often have a viewing period before the formal presentation. Trainees should be encouraged to engage attendees by offering to summarize the poster for them. This allows the trainee to rehearse his or her oral presentation and often stimulates dialog between the attendee and the trainee. This generally helps to relax the trainee and sharpens his or her oral presentation.

\section{Summary}

Teaching research to those with or pursuing undergraduate-level education is predicated on acknowledging that research traditionally has been the purview of graduate school. Therefore, a department-based research program requires the careful and nurturing cultivation of higherlevel cognitive skills as well as new technical skills. It also requires consideration of what types of projects realistically can be pursued. Prerequisites include individuals within a department or educational program with strong leadership and mentoring skills, and the ability to identify and develop trainees with an abundance of curiosity and an aptitude for engaging in research.

\section{ACKNOWLEDGMENTS}

I thank John Kelly RRT, former technical director of the University of California-San Francisco, San Francisco General Hospital Respiratory Care Services, whose support and vision were responsible for the creation of the department's research program and to my dedicated therapistcoinvestigators, without whom this article could not have been written.

\section{REFERENCES}

1. Dewey J. How we think. Mineloa, NY: Dover Pub; 1997:8-9.

2. Ziman J. What is science? In: Klemke ED, Rudge DW, Kine AD, editors. Introductory readings in the philosophy of science. Amherst, NY: Promethius Books; 1998:48-53.

3. Bloom BSE, Furst EJ, Hill WH, Krathwohl DR. Taxonomy of educational objectives: The classification of educational goals. Handbook I. New York: David McKay; 1956.

4. Kahneman D. Thinking fast and slow. New York: Farrar, Straus and Giroux; 2011.

5. Kuhn TS. Logic of discovery or psychology of research. In: Curd M, Cover JA, editors. Philosophy of science. The central issues. New York: W.W. Norton; 1998:11-19.

6. Hein P. Grooks. New York: Doubleday; 1968.

7. Acute Respiratory Distress Syndrome Network, Brower RG, Matthay MA, Morris A, Schoenfeld D, Thompson BT, Wheeler A. Ventilation with lower tidal volumes as compared with traditional tidal volumes for acute lung injury and the acute respiratory distress syndrome. $\mathrm{N}$ Engl J Med 2000;342(18):1301-1308.

8. Kallet RH, Alonso JA, Luce JM, Matthay MA. Exacerbation of acute pulmonary edema during assisted mechanical ventilation using a lowtidal volume, lung-protective ventilator strategy. Chest 1999;116 (6):1826-1832.

9. Kallet RH, Alonso JA, Diaz M, Campbell AR, Mackersie RC, Katz JA. The effects of tidal volume demand on work of breathing during simulated lung-protective ventilation. Respir Care 2002;47 (8):898-909. 


\section{RESEARCH IN RESPIRATORY CARE}

10. Kallet RH, Campbell AR, Dicker RA, Katz JA, Mackersie RC. Effects of tidal volume on work of breathing during lung-protective ventilation in patients with acute lung injury and acute respiratory distress syndrome. Crit Care Med 2006;34(1):8-14.

11. Kallet RH, Campbell AR, Dicker RA, Katz JA, Mackersie RC. Work of breathing during lung-protective ventilation in patients with acute lung injury and acute respiratory distress syndrome: a comparison between volume and pressure-regulated breathing modes. Respir Care 2005;50(12):1623-1631.

12. Pangilinan LP, Mangalindan ER, Summers TJ, Yip V, Kallet RH. Expiratory pause maneuver (EPM) to assess muscle pressure (Pmus) during simulated assisted mechanical ventilation (AMV). Part 1: Feasibility. Respir Care 2018;63(Suppl 10):3020675.

13. Pangilinan LP, Mangalindan ER, Summers TJ, Yip V, Kallet RH. Expiratory pause maneuver (EPM) to assess muscle pressure (Pmus) during simulated assisted mechanical ventilation (AMV). Part 2: Intraand inter-observer reproducibility. Respir Care 2018;63(Suppl 10):3020719.

14. Summers TP, Phillips JS, Mangalindan ER, Yip V, Kallet RH. Expiratory pause maneuver (EPM) to assess muscle pressure (Pmus) during simulated assisted mechanical ventilation (AMV). Part 3: Effects of chest mechanics. Respir Care 2018;63(Suppl 10):3020779. 